\title{
La función inspectora en materia de sociedades cooperativas
}

\author{
Luis Ángel Díez Ácimas \\ Funcionario de la Administración General del Estado. \\ Ex coordinador de Servicios de la Dirección de Economía Social de Castilla y León
}

Sumario: I. Introducción. II. Las cooperativas y la Administración Pública. 1. Fomento del cooperativismo. 2. Registro de Sociedades Cooperativas. 3. Función inspectora. III. Normativa aplicable. 1. Ámbito estatal. 2. Ámbito autonómico. IV. Atribución de la función inspectora. V. Sujetos responsables. VI. Infracciones, 1. Clasificación de las infracciones. 2. Prescripción de las infracciones. VII. Sanciones. 1. Tipo de sanciones. 2. Graduación y cuantía de las sanciones. 3. Reincidencia. 4. Persistencia o continuidad en la infracción. 5. Competencia. 6. Prescripción de las sanciones. VIII. Procedimiento sancionador. IX. Intervención temporal de la cooperativa. X. Descalificación. 1. Causas de la descalificación. 2. procedimiento. 3. Efectos. XI. Conclusiones. Bibliografía.

Resumen: Las diferentes leyes reguladoras de las sociedades cooperativas en el Estado Español recogen en su articulado una parte dedicada a fijar las líneas básicas de las relaciones de este tipo de sociedades con la administración pública, incluyendo el ejercicio de la función inspectora y sancionadora por parte de ésta en materia de sociedades cooperativas.

Partiendo del análisis de las diferentes leyes, se realiza este estudio sobre dicha función inspectora, reflejando como se recogen en aquéllas, materias tales como la atribución de la función inspectora, los sujetos responsables, la tipificación de infracciones y sanciones, las normas básicas del procedimiento sancionador, así como las medidas de intervención temporal de las cooperativas y su descalificación, lo que nos permitirá concluir que, también, en esta materia hay considerables diferencias entre las leyes aplicables.

Palabras clave: Cooperativa. Administración. Infracciones. Sanciones. Descalificación.

Abstract: The different laws governing cooperatives in Spain collect in its articles the guidelines of relationship between such societies and public administration, including the exercise of the inspection and sanctioning function by this on cooperatives. 
This study about the inspection function is based on the analysis of the different laws, and express how different subjects are included on them, for example subjects as the inspection function, parties responsible, the typification of infractions and penalties, the basic rules of disciplinary proceedings, the measures for temporary intervention in cooperatives and their disqualification, allowing us to conclude that also in this area there is considerable differences between the applicable laws.

Key words: Cooperative. Public Administration. Infractions. Sanctions. Disqualification. 


\section{Introducción}

Las diferentes leyes reguladoras de las sociedades cooperativas en el Estado Español recogen, invariablemente, en su articulado una parte dedicada a fijar las líneas básicas de las relaciones de este tipo de sociedades, en su condición específica de tales, con las administraciones públicas. Así, se fijarán las obligaciones relativas al Registro de Cooperativas radicado en todos los casos en el seno de la administración, unas líneas básicas sobre lo que debe ser la política pública de fomento de estas entidades y el ejercicio de la función inspectora y sancionadora de la administración en materia de sociedades cooperativas. También, podemos incluir en este apartado, la creación y regulación que, a veces, se realiza en las propias leyes sobre sociedades cooperativas, de consejos de cooperativismo o de economía social, como foros de encuentro de la administración con los agentes representativos del sector y como órganos consultivos y asesores en materia de promoción y difusión de estas formas de hacer empresa.

En el presente estudio, partiendo del marco de relaciones referido, nos centraremos en el ejercicio de la función inspectora, analizando la atribución de la misma, la determinación de los sujetos responsables, la tipificación de infracciones y sanciones, el procedimiento sancionador y haremos una especial referencia a las medidas de intervención temporal y a la descalificación de las sociedades cooperativas por parte de la administración. Para ello, analizaremos y haremos referencia a las diferentes leyes aplicables a esta materia.

\section{Las cooperativas y la Administración Pública}

Tradicionalmente, ha existido una especial relación entre las cooperativas y las administraciones públicas y esto obedece, históricamente, a la intención del poder político de controlar este tipo de entidades, al ser incluidas entre las que no tienen por único y exclusivo objeto el ánimo de lucro. El estado liberal del siglo XIX, nacido de la Revolución Francesa, manifestó una gran hostilidad hacia las asociaciones que permitían al individuo organizarse para la realización de intereses de naturaleza no lucrativa en cuanto que éstas, a diferencia de las lucrativas, cuyos fines eran claros e inocuos para el estado, podían realizar actividades contrarias a la autoridad de éste ${ }^{1}$. Ello, si cabe, adquiría una ma-

1 En este sentido, GIRÓN, J.: «Los conceptos y tipos de sociedad en los Códigos Civil y de Comercio y sus relaciones», en Estudios del Centenario de la Ley del Notariado, Madrid, 1964, p. 22, y Derecho de Sociedades, tomo I, Madrid, 1976, pp. 32 y 33; LLo- 
yor significación en el caso de las sociedades cooperativas por, ser evidente, la actitud encontrada del cooperativismo, en su nacimiento, con el orden socioeconómico establecido².

Como manifestación de esta voluntad de control podemos indicar el régimen de constitución de las cooperativas en aplicación de la Ley de Asociaciones de 1887, éstas están sujetas a una declaración de licitud tácita o previa a cargo del gobernador de la provincia, que deberá remitir inmediatamente copia certificada de los documentos enviados por los fundadores o iniciadores de la asociación al tribunal o juzgado competente si, de su contenido, pudiesen deducirse dudas sobre su licitud con arreglo a las prescripciones del Código Penal.

La primera Ley de Cooperativas, aprobada en 1931, establece un régimen jurídico más flexible que la Ley de Asociaciones, aunque muy distinto al de las demás sociedades de fines económicos, donde se sigue apreciando un amplio intervencionismo en la creación de este tipo de entidades. Además, se establece una regulación, seguida en la legislación española posterior, por la que se configura un sistema registral radicado en la administración. Esta primera ley española de cooperativas ya incluye normas sancionadoras.

La situación cambia de nuevo con la Ley de Cooperativas de 1942. Con ella se acentúa el control gubernativo, en cuanto que con carácter preceptivo se exige un informe de la Delegación Nacional de Sindicatos, a través de la Obra Sindical de Cooperación sobre la necesidad o conveniencia de la cooperativa.

En cambio, la Ley de Cooperativas de 1974, es bastante novedosa en algunos aspectos de los que aquí nos interesan, principalmente, se atribuye un nuevo carácter al Registro de Cooperativas ${ }^{3}$. No obstante, hasta 1977 todavía es necesario para la constitución de una cooperativa el informe de la Obra Sindical de Cooperación. La necesidad de

BREGAT, M.L.: Mutualidad y empresas cooperativas, Bosch, Barcelona, 1990, p. 158. Puede verse también PAz-Ares, C.: Comentario del Código Civil, tomo II, 2. ${ }^{a}$ ed., Civitas, Madrid, 1993, pp. 1307 y ss.

2 Divar, J.: Introducción al cooperativismo, en I Jornadas de Cooperativas de Euskadi, 1882, p. 12.

3 A partir de esta Ley, el Registro de Cooperativas, deja de ser un registro administrativo puro al envolver en su estructura administrativa el continente de efectos jurídicos, es decir, a partir de ella tendrá cuerpo de registro administrativo y vestido de registro jurídico. Como señala el artículo 4.3 de la Ley: «El Registro General de Cooperativas, dependiente del Ministerio de Trabajo se organizará ajustándose en su eficacia a los principios de publicidad formal y material, legalidad y legitimación». Posteriormente, el Reglamento aprobado en 1978 dedica a la regulación del Registro de Cooperativas el capítulo VIII (arts. 86 a 92). 
dicho informe cesa con el Real Decreto Ley 31/1977, de 2 de junio 4 . Desde la promulgación de esta norma y, sobre todo, desde el reconocimiento, sin traba alguna, por el artículo 22 de la Constitución Española de 1978 (CE), del derecho de asociación, la creación de las sociedades cooperativas se rige por el principio de libre constitución dentro del respeto a las correspondientes disposiciones normativas.

En la actualidad, podemos concretar en tres grandes apartados la actuación de la administración pública respecto de las sociedades cooperativas, que serían la política de fomento de este tipo de entidades, el Registro de Sociedades Cooperativas y el ejercicio de la función inspectora y sancionadora respecto de las mismas.

\section{Fomento del cooperativismo}

El cooperativismo, además de su importancia en un sentido estrito económico-empresarial tiene una dimensión social muy relevante derivada, básicamente, de los principios y valores que le son propios; y generalmente, reconocidos. Sólo, teniendo en cuenta esto, se puede explicar el interés constitucional por las sociedades cooperativas, que viene consagrado en el artículo 129.2 de la CE.

El interés del legislador por este tipo de sociedades y su fomento se reitera en la legislación estatal, como demuestra la Ley 5/2011, de 29 de marzo, de Economía Social ${ }^{5}$ y las diferentes leyes de cooperativas, que fijan como objeto de las mismas, no sólo su regulación, sino, también, establecer las directrices básicas de las medidas para su fomento.

Como decíamos anteriormente, las administraciones públicas vienen obligadas a realizar actuaciones de fomento del cooperativismo por imperativo derivado directamente de la CE. Ésta realiza declaraciones importantes en apoyo del cooperativismo y de la economía social. Su artículo 129.2 dispone que «Los poderes públicos promoverán eficazmente las diversas formas de participación en las empresas y fomentarán mediante una legislación adecuada las sociedades cooperati-

${ }^{4}$ El Real Decreto Ley 31/1977, de 2 de junio, sobre extinción de la sindicación obligatoria, reforma de estructuras sindicales y reconversión del Organismo Autónomo «Administración Institucional de Servicios Socio-Profesionales», en su disposición adicional segunda faculta al Gobierno para adecuar la organización y estructuración del movimiento cooperativista a los principios de autonomía y libertad asociativa.

5 El artículo 8 de la ley se dedica al fomento y difusión de la economía social. En el apartado 1, se reconoce como tarea de interés general, la promoción, estímulo y desarrollo de las entidades de la economía social y de sus organizaciones representativas. 
vas. También establecerán los medios que faciliten el acceso de los trabajadores a la propiedad de los medios de producción».

Este precepto constitucional hace varias afirmaciones de trascendencia, como señala Calvo Ortega ${ }^{6} ; \mathrm{y}$, todas ellas de futuro. El texto indica "promoverán, fomentarán y establecerán». Es un mandato del constituyente a todos los poderes públicos, tanto estatales, como autonómicos; e, incluso, locales. Este mandato constitucional exige la acción de fomento a las Cortes Generales por su función legislativa y parlamentaria, al poder judicial y al Tribunal Constitucional, en cuanto interpretadores de las normas, al poder ejecutivo, en cuanto Gobierno Central y Administración General del Estado, a las comunidades autónomas, con competencias en materia de cooperativas, tanto a sus poderes ejecutivos y legislativos y a las administraciones locales, que en sus políticas de proximidad al territorio y a los ciudadanos pueden contribuir de muy diversas maneras (aportando medios materiales, instalaciones, recursos técnicos, servicios compartidos,... e incluso participando directamente en los proyectos como socios colaboradores) a la creación, desarrollo y consolidación de las sociedades cooperativas.

La CE, reiteramos, impone a los poderes públicos esta obligación. Se trata de una cláusula de mandato y no de habilitación. Estos poderes tienen el deber de fomentar y promover las sociedades cooperativas; $y$, además, hacerlo a través «de una legislación adecuada».

El Tribunal Constitucional (TC) ha declarado, en constante jurisprudencia, que las normas constitucionales, lejos de poseer un significado simplemente programático, necesitado de ulterior desarrollo legislativo para adquirir validez y eficacia, tienen un carácter obligatorio y vinculante con proyección general, que alcanza consecuentemente al completo elenco de poderes públicos, de un lado, así como a la totalidad de ciudadanos de otro ${ }^{7}$.

El problema puede manifestarse al plantearnos cómo pueden exigir los ciudadanos a estos poderes que cumplan dicho mandato. Pero,

6 Calvo Ortega, R.: «Las figuras de la Economía Social en la Constitución española de 1978». CIRIEC-España, n. ${ }^{\circ} 47,2003$, pp. 159-174.

7 El Tribunal Constitucional ha afirmado el valor normativo y la inmediata aplicabilidad de la Constitución. afirmando que «lejos de ser un mero catalogo de principios de no inmediata vinculación y de no inmediato cumplimento hasta su desarrollo por vía legal, es una norma jurídica, la norma suprema de nuestro ordenamiento, y en cuanto tal, tanto los ciudadanos como los poderes públicos, y, por consiguiente, también los jueces y magistrados del poder judicial, están sujetos a ella» (STC 16/1982, de 28 de abril). En Rodrigo RuIz, M.A.: "Mandato constitucional de fomento y fiscalidad de las cooperativas». CIRIEC-España, n. ${ }^{\circ} 47,2003$, pp. 199-219. 
la dificultad de la exigencia o de la concreción de lo exigible no puede empañar la claridad y la naturaleza del precepto.

De cualquier manera, estamos ante una imprecisión relativa, según Calvo Ortega, ya que puede decirse que las normas deben de ser más favorables para este tipo de sociedades que para el modelo social que deba considerarse normal. La pregunta que nos formulamos es ¿en qué debe consistir esta mejor consideración legislativa?. Puede ser administrativa, crediticia, de ayuda a la formación específica, tributaria, laboral, etc. Pero lo cierto es que tales normas tienen que ser más ventajosas desde una perspectiva patrimonial (que es la única que aquí puede contemplarse) que las que se aplican a los otros sujetos societarios.

Es difícil decir si el precepto constitucional que estamos examinando ha jugado un papel importante en la creación de sociedades cooperativas. Aunque podamos mostrar cifras positivas del periodo constitucional, siempre queda la duda, según Calvo Ortega, de saber si el desarrollo que se ha producido es debido al revulsivo de incluir este precepto en la norma constitucional o a otras razones. Entre éstas, destaca el esfuerzo admirable de muchos trabajadores creando y manteniendo empresas asociativas en condiciones siempre difíciles.

No podemos ocultar que existen voces discrepantes con la existencia de medidas específicas favorecedoras de las cooperativas; pero, los motivos para que éstas existan son claros. Estas sociedades gozan de principios y valores (gestión democrática, prioridad de la persona sobre el capital,...), así como de ventajas y potencialidades (creación de empleo estable y de calidad, fijación de población al territorio, generación de cohesión social, modernización y profesionalización del sector agrario, contribución al desarrollo rural, ...) que las hacen merecedoras de un tratamiento específico. Pero, si esto no fuera suficiente para acreditar las medidas de discriminación positiva que puedan otorgarse a las cooperativas, hay que recordar que existe un motivo de excepcional relevancia que justifica ese trato y es el hecho de que éstas dotan fondos, con finalidades específicas, que son irrepartibles cuando los socios abandonan la cooperativa o ésta se transforma en otro tipo de sociedad e, incluso, cuando la misma desaparece ${ }^{8}$. Esto exige que la legis-

8 Rodrigo Ruiz, M.A. "Mandato constitucional de fomento y fiscalidad de las cooperativas» CIRIEC-España, Revista de Economía Pública, Social y Cooperativa, n. ${ }^{\circ} 47$, extraordinario, noviembre de 2003, pp. 199-219. Esta importantísima limitación patrimonial distingue de modo esencial a las cooperativas de las sociedades capitalistas, desde el punto de vista económico, y supone para las primeras un mecanismo peculiar de contribución a la comunidad que demanda, en buena técnica fiscal, medidas correctoras, pues afecta y reduce la capacidad contributiva que en éstas puede ser gravada. Dicho 
lación cooperativa sea fiel a los principios y valores a los que va unido tradicionalmente el cooperativismo, ya que las medidas legales excesivamente flexibilizadoras del modelo podrían conllevar una pérdida de identidad del mismo y, como consecuencia de ello, de ese trato favorable. Si no son unas empresas claramente diferentes del resto no sería necesario este precepto constitucional, bastaría con el reconocimiento que hace el artículo 38 a la libertad de empresa en el marco de la economía de mercado.

\section{Registro de Sociedades Cooperativas}

Siguiendo la tradición, antes referida y comenzada con la ley republicana de 1931, la normativa en materia de cooperativas ha configurado un sistema registral de carácter administrativo, aunque las variaciones introducidas al respecto por las sucesivas normas reguladoras, han dotado a estos registros de auténticos efectos jurídicos.

Junto con la actividad de fomento, la actividad de registro es la tarea fundamental a realizar por la administración en relación con las sociedades cooperativas. Su labor es muy relevante para las propias empresas (no olvidemos que con la inscripción en el correspondiente Registro de Cooperativas se adquiere personalidad jurídica y la obligatoriedad de inscribir todos los actos con relevancia en la vida social de la cooperativa) y para la sociedad en general, al ser el garante de la seguridad jurídica, tan necesaria en el tráfico empresarial.

Las legislaciones suelen destacar la importancia del Registro de Cooperativas en la persecución de las infracciones, al imponer a éste la obligación de comunicar a los órganos inspectores los incumplimientos de los que tenga constancia.

\section{Función inspectora}

Estas sociedades son objeto de inspección y posible procedimiento sancionador en cualquier otra materia (laboral, consumo, tributaria, transportes, medio ambiente...), como el resto de empresas con independencia de su fórmula jurídica, por la administración competente en

de otro modo, ya que buena parte del patrimonio social obtenido con el esfuerzo particular de sus miembros termina revertiendo a la comunidad, parece lógico que las cooperativas contribuyan al sostenimiento de las cargas públicas destinando un menor porcentaje de sus beneficios regulares o periódicos al pago de impuestos. 
cada materia y de acuerdo a la normativa específica de cada una de ellas.

Aquí, nos referimos por tanto, de forma exclusiva a la función inspectora respecto al cumplimiento de la legislación cooperativa, tanto en el momento de su constitución, como durante la vida de la misma, es decir, por las actuaciones societarias de este tipo de empresas. Las leyes de cooperativas incluyen dentro de las obligaciones de la administración respecto a las cooperativas, con carácter general, una parte dedicada a la función inspectora.

Nos hallamos ante una potestad de carácter instrumental derivada de la competencia material. El TC ha avalado la posibilidad de que las comunidades autónomas adopten normas administrativas sancionadoras cuando ostentan la competencia sobre la materia sustantiva de que se trate.

La primera cuestión que debemos plantearnos es si resulta necesario un sistema de inspección propio y específico para este tipo de sociedades. La respuesta no es fácil. Hay quien lo justifica exclusivamente como el precio a pagar por el fomento público del cooperativismo. Esto es excesivamente simple. Hablábamos anteriormente de la consideración constitucional a la sociedad cooperativa, lo que le reconoce una naturaleza diferenciada de otros tipos de empresas y se exige una legislación específica para las mismas que favorezcan su labor permanente como instrumento de promoción social y que dé respuesta a la función económica y social que le es propia. La cooperativa es un instrumento que suscita interés social y su fomento es de interés general por lo que deben tener una normativa específica, incluida la que pretende rectificar las actuaciones que pongan en peligro sus principios o su propia naturaleza.

Cuando la administración otorga a una empresa la oportuna calificación como empresa de trabajo temporal o servicio de prevención ajeno, pongamos por ejemplo, abre a éstas un nuevo abanico de obligaciones específicas que si son incumplidas serán objeto del oportuno procedimiento sancionador, no en cuanto compañías mercantiles, sino en cuanto ETT o SPA específicamente. Es decir, si incumplen las obligaciones que la normativa las impone por tener esa calificación, se enfrentan a un régimen sancionador específico. En el caso de las cooperativas, que no se definen por su actividad como los ejemplos señalados; sino por su propia naturaleza, está más justificada aún que no se desvirtúe ésta; y, por tanto, entendemos legitima la actuación inspectora para impedir que bajo la denominación de sociedad cooperativa se camuflen empresas que no participan de los elementos esenciales de su configuración. 


\section{Normativa aplicable}

\section{1. Ámbito estatal}

Con la entrada en vigor de la Ley 8/1988, de 7 de abril, de Infracciones y Sanciones en el Orden Social, como explican García Trascasas y Reguero Celada9 ${ }^{9}$, se pretendió aglutinar en una única norma el derecho administrativo sancionador del orden social. Esta intención se vio truncada años después, ya que se vivió un proceso de dispersión de las infracciones sociales, al recogerse éstas en diferentes normas (Ley 14/1994, de 1 de junio, de Empresas de Trabajo Temporal, Real Decreto Legislativo 1/1995, de 24 de marzo, por el que se aprueba el texto refundido de la Ley del Estatuto de los Trabajadores, Ley 31/1995, de 8 de noviembre, de Prevención de Riesgos Laborales, Ley 27/1999, de 16 de julio, de Cooperativas). Posteriormente, se retoma la idea de concentración de las normas sobre infracciones y sanciones en el orden social en una única norma legal, que culmina con el Real Decreto Legislativo 5/2000, de 4 de agosto, por el que se aprueba el texto refundido de la Ley de Infracciones y Sanciones en el Orden Social (LISOS).

La ley 27/1999, de 16 de julio, de Cooperativas (LCOOP) dedicaba su artículo 114 a tipificar las infracciones y su prescripción y el artículo 115 a fijar las sanciones y establecer el procedimiento para su imposición. Estos fueron derogados por la LISOS, pasando a estar regulada esta materia por dicha norma, que dedica su artículo 38 a las infracciones en materia de cooperativas.

Las sociedades cooperativas, según establece la propia norma, únicamente se verán afectadas por las previsiones de la LISOS en tres supuestos:

- Cuando la legislación autonómica se remita al respecto a la legislación del Estado.

- Cuando no se haya aprobado la legislación autonómica sobre la materia.

- Cuando las cooperativas desarrollen su actividad cooperativizada en el territorio de varias comunidades autónomas, de acuerdo con lo establecido en la LCOOP.

9 García Trascasas, A. y Reguero Celada, J. "La Inspección de Trabajo ante el hecho cooperativo. La descalificación de las cooperativas», en Economía social y cooperativismo (dir. Morgado Panadero, P. y coord. Burgos Rosado, L.). Editorial Lex Nova, S.A. 2006. pp. 251-275. 
Como consecuencia de los criterios descritos, la normativa que será aplicable más habitualmente será la autonómica que corresponda en función del ámbito territorial de la sociedad cooperativa.

\section{2. Ámbito autonómico}

De acuerdo con la distribución competencial derivada de la CE las comunidades autónomas tienen competencia plena en materia de sociedades cooperativas y prácticamente todas ellas han aprobado su normativa específica, de aplicación en su respectivo ámbito territorial. Por lo tanto, las comunidades autónomas pueden regular la constitución y las normas básicas de organización y funcionamiento de las cooperativas y, también, su régimen sancionador, determinando las acciones u omisiones constitutivas de infracción, las sanciones aplicables y los sujetos responsables. La legislación estatal (LCOOP y LISOS) sólo será aplicable en los supuestos en que esas propias normas así lo determinen.

El marco normativo autonómico vigente en materia de Sociedades Cooperativas es el que se señala a continuación, con indicación de los artículos destinados a la regulación de la función inspectora:

- Ley 4/1993, de 24 de junio, de Cooperativas de Euskadi (LCE). Artículos 139-142.

- Ley 2/1998, de 26 de marzo, de Sociedades Cooperativas de Extremadura (LCEX). Artículos 169-181.

- Ley 5/1998, de 18 de diciembre, de Cooperativas de Galicia (LCG). Modificada en esta materia por la Ley 14/2011, de 16 de diciembre. Artículos 139-141.

- Ley 4/1999, de 30 de marzo, de Cooperativas de la Comunidad de Madrid (LCCM). Artículos 131-135.

- Ley 4/2001, de 2 de julio, de Cooperativas de La Rioja (LCLR). Artículos 139-142.

- Ley 4/2002, de 11 de abril, de Cooperativas de la Comunidad de Castilla y León (LCCyL). Artículos 136-139.

- Ley 18/2002, de 5 de julio, de Cooperativas de Cataluña (LCCAT). Artículos 134-138.

- Ley 1/2003, de 20 de marzo, de Cooperativas de las Islas Baleares (LCIB). Artículos 146-149.

- Ley 8/2003, de 24 de marzo, de Cooperativas de la Comunidad Valenciana (LCV). Artículos 116-121.

- Ley 8/2006, de 16 de noviembre, de Sociedades Cooperativas de la Región de Murcia (LCMU). Artículos 138-141. 
- Ley Foral 14/2006, de 11 de diciembre, de Cooperativas de Navarra (LFCN). Dedica el artículo 62 a la regulación de la descalificación, no haciendo más precisiones sobre el régimen de inspección y sanción. Es, por tanto, la única ley que no regula expresamente un catálogo de infracciones y sanciones..

- Ley del Principado de Asturias 4/2010, de 29 de junio, de Cooperativas (LCAS). Artículos 203-208.

- Ley 11/2010, de 4 de noviembre, de Cooperativas de CastillaLa Mancha (LCCLM). Artículos 158-162.

- Ley 14/2011, de 23 de diciembre, de Sociedades Cooperativas Andaluzas (LCAND). Artículos 120-126.

- Ley de Cantabria 6/2013, de 6 de noviembre, de Cooperativas de Cantabria (LCCANT). Artículos 144-148.

- Decreto Legislativo 2/2014, de 29 de agosto, del Gobierno de Aragón, por el que se aprueba el texto refundido de la Ley de Cooperativas de Aragón (LCAR). Artículos 94-96.

Las regulaciones normativas sobre la materia deben respetar, en todo caso, los principios de la potestad sancionadora y del procedimiento sancionador previstos en los artículos 127 y ss. de la Ley 30/1992, de 26 de noviembre, de Régimen Jurídico de las Administraciones Públicas y del Procedimiento Administrativo Común (LRJAPyPAC).

Estos principios de la potestad sancionadora son legalidad, irretroactividad, tipicidad, responsabilidad, proporcionalidad, prescripción y concurrencia.

En lo que respecta al procedimiento sancionador, se deberá garantizar el respeto a los principios formales que deben regir éste, tales como la necesidad de tramitar el oportuno procedimiento con sus distintas fases, el derecho a la información (hechos imputados, posibles sanciones aplicables, identidad del instructor, autoridad competente para imponer la sanción) y a la defensa, manifestaciones de la presunción de inocencia, que determina que la carga de la prueba de los hechos constitutivos de la infracción recaiga sobre la administración, con la prohibición de utilizar pruebas obtenidas con vulneración de derechos fundamentales, el derecho a no declarar contra sí mismo, el derecho a efectuar alegaciones o el derecho de utilización de los medios de prueba propuestos ${ }^{10}$.

10 STC 81/2000, de 27 de mayo, se refiere a todos estos aspectos. 


\section{Atribución de la función inspectora}

Se otorga la función inspectora al actual Ministerio de Empleo y Seguridad Social en el ámbito estatal y a la consejería competente en materia de cooperativas en el respectivo ámbito autonómico. Esta potestad se ejercerá a través de la Inspección de Trabajo y Seguridad Social (ITSS), en el supuesto de competencia ministerial y en la mayor parte de comunidades autónomas. No debe olvidarse la previsión que realiza la disposición adicional sexta de la Ley 42/1997, de 14 de noviembre, Ordenadora de la ITSS, en virtud de la cuál, las comunidades autónomas podrán otorgar la función inspectora en materia de sociedades cooperativas a funcionarios ajenos al sistema de ITSS. Únicamente, la LCE, la LCV, la LCCLM y la LCAND, no atribuyen esa función expresamente a la ITSS. En unos casos se remiten a desarrollo reglamentario y en otros se atribuye a órganos propios de la consejería competente por razón de la materia.

Como vemos, cabe la posibilidad de otorgar la actividad inspectora a funcionarios propios de la consejería competente en la materia; pero, la experiencia de otorgar este tipo de funciones a personal que no pertenece a cuerpos específicos de inspección, sino a funcionarios conocedores de la materia sustantiva en los aspectos objeto de control, se ha mostrado poco eficaz, dada la falta de preparación en labores de investigación, apreciación y valoración de hechos, calificación de éstos, tipificación de la presunta infracción, su graduación, reacción ante situaciones delicadas en el ejercicio de la función inspectora... por lo que se considera oportuno que cuando no se atribuya esta competencia a la ITSS se otorgue ésta a un cuerpo específicamente inspector de la comunidad autónoma respectiva, lo cuál no es muy factible en las de pequeña dimensión, lo que justifica la masiva atribución competencial a la ITSS.

No se contempla en la mayor parte de normas la posibilidad de que ejerzan funciones inspectoras las entidades asociativas de cooperativas respecto a sus asociadas, como contempla el artículo 139 de la LCE. Al tratarse de organizaciones privadas, que establecen sus normas de funcionamiento y el grado de exigencia a sus asociados, nada impide que sus estatutos prevean esas actividades de control de aquéllos ${ }^{11}$; pero, no debe confundirse, en ningún caso, con la labor inspectora de la ad-

11 Martínez Maneiro, B.: «Estudio del régimen de inspección y sanción en la ley de sociedades cooperativas de Euskadi y comparativa con la regulación de esta materia en el resto de leyes cooperativas autonómicas vigentes y la ley estatal». GEZKI, n. ${ }^{\circ} 3,2007$, pp. 41-63. 
ministración, por lo que no se debería regular paralelamente a la función inspectora, ni otorgar tal denominación a esas posibles actividades de las entidades asociativas.

Algunas leyes definen el carácter preventivo de la función inspectora o regulan que el inspector podrá limitarse a formular advertencias o recomendaciones encaminadas al efectivo cumplimiento de la ley. Otras normas, no se refieren a este asunto; pero, creemos que resulta innecesario cuando sea competente la ITSS, ya que a la luz de la regulación estatal de la actividad inspectora de ésta, se conciben las actuaciones de advertencia y recomendación como normales. El artículo 7 de la ley 42/1997, de 14 de noviembre, Ordenadora de la Inspección de Trabajo y Seguridad Social recoge expresamente, como posibles acciones a realizar en el marco de la actuación inspectora, las advertencias y recomendaciones. En el mismo sentido, se manifiesta, de conformidad con lo previsto por los Convenios 81 y 129 de la Organización Internacional del Trabajo, el artículo 49 de la LISOS. Por lo tanto, las actuaciones de advertencia y recomendación forman parte de la actuación ordinaria en todas las materias competencia de la ITSS, incluida la de cooperativas.

\section{Sujetos responsables}

Solamente se podrá imponer una sanción por hechos constitutivos de infracción administrativa a las personas físicas o jurídicas que resulten responsables de los mismos aún a título de simple inobservancia (artículo 139.1 de la LRJAPyPAC), lo que incluiría, como indica la jurisprudencia, el dolo, la imprudencia, la negligencia o la ignorancia inexcusable.

Se aprecia en la legislación aplicable un régimen muy dispar en cuanto a quienes pueden ser los sujetos responsables de las infracciones en materia de sociedades cooperativas. Veamos los diferentes supuestos que se recogen en las normas españolas de cooperativas:

- Responsabilidad exclusivamente de la sociedad cooperativa. Esta postura (LCCYL, LCMU, LCAS, LCCLM y LCCANT) considera únicamente como sujetos responsables a las sociedades cooperativas por las acciones $u$ omisiones contrarias a la ley, a sus normas de desarrollo y a las disposiciones complementarias contenidas en los estatutos. Añadiendo, a continuación, sin perjuicio de las responsabilidades personales exigibles a consejeros, interventores y liquidadores, con lo que sólo cabría actuar contra ellos ejerciendo las correspondientes acciones de responsabilidad. 
- Responsabilidad de la cooperativa y posible responsabilidad de los cargos sociales. Considera como sujetos responsables a las sociedades cooperativas, con independencia de la responsabilidad en que incurran los integrantes de órganos sociales cuando le sean imputables con carácter solidario o personal, bien de forma directa o porque pueda ser exigida por derivación de responsabilidad. Se abre, pues, una posibilidad a la responsabilidad directa (LCIB, LCLR, LCG).

- Responsabilidad de la sociedad cooperativa y alternativamente responsabilidad de las personas que ocupan cargos en la misma. Así, la LCAND, la LCAR y LCEX entienden que son sujetos responsables las cooperativas; $y$, en su caso, los miembros de los órganos sociales o los liquidadores, cuando la infracción les sea personalmente imputable. Esta misma postura mantiene la LCCAT ${ }^{12}$, pero fijando con mayor precisión los posibles sujetos responsables.

- Responsabilidad de los titulares de los órganos u otros cargos de la cooperativa y alternativamente, la sociedad cooperativa. La LCE establece un listado de posibles responsables cuando les sean personalmente imputables las infracciones (administradores, directores, miembros de la comisión de vigilancia y liquidadores) y casi de forma residual se alude a la cooperativa ${ }^{13}$.

- Responsabilidad en unos supuestos de infracción de la sociedad cooperativa y otros en los que son responsables los miembros de los órganos sociales. La LCV hace un esfuerzo mayor con la voluntad de establecer la responsabilidad de las personas que, dentro de la sociedad, y de acuerdo con lo estipulado en la ley y en sus estatutos, son responsables ${ }^{14}$, y fijando su exclusiva respon-

12 Artículo 134.2 de la Ley 18/2002, de 5 de julio, de Cooperativas de Cataluña. "La vulneración de los preceptos de la presente Ley y de los estatutos sociales supone la responsabilidad de la cooperativa y, en todo aquello que les sea directamente imputable, la responsabilidad de todos los miembros del consejo rector, de la intervención de cuentas, de la dirección o la gerencia, de las personas con poderes generales y de los liquidadores, que pueden ser sancionados por las infracciones establecidas por el artículo 135, si resultan responsables de las mismas».

13 Artículo 139.2 de la Ley 4/1993, de 24 de junio, de Cooperativas de Euskadi. «Son sujetos responsables de las acciones u omisiones que entrañen el incumplimiento de esta ley y de sus normas de aplicación y desarrollo, los administradores, los directores, los miembros de la Comisión de Vigilancia y liquidadores en cuanto les sea personalmente imputable, así como, en su caso, las sociedades cooperativas.

14 Artículo 117.3 de la Ley 8/2003, de 24 de marzo, de Cooperativas de la Comunidad Valenciana «las infracciones a la legislación cooperativa cometidas por las entidades cooperativas y por los miembros de sus órganos sociales, a los efectos de su sanción administrativa, se clasificarán en muy graves, graves y leves». 
sabilidad en dos infracciones en materia de actuaciones en situación de conflicto de intereses ${ }^{15}$.

\section{Infracciones}

El principio de tipicidad, de acuerdo con el artículo 129.1 de la LRJAPyPAC, supone que únicamente constituyen infracciones administrativas las vulneraciones del ordenamiento jurídico previstas como tales infracciones por una ley. Éstas deberán ser clasificadas como leves, graves o muy graves por una norma de dicho rango. Así todas las leyes analizadas (salvo la LFCN, como ya se ha señalado) establecen un catálogo de infracciones, clasificadas en las tres categorías indicadas.

El panorama es dispar. Partiendo de unas ideas generales similares, la tipificación de infracciones experimenta importantes diferencias entre unas leyes y otras, en cuanto al número de infracciones recogidas, la calificación de las mismas y sobre la propia calidad en la tipificación de los tipos recogidos. Este último supuesto se aprecia, especialmente, en las cláusulas generales para dar cobertura a las infracciones leves.

En cuanto al número de infracciones tipificadas, podemos observar que éste va desde las nueve que recoge la LISOS o las once de la LCAS, hasta las veintiséis de la LCV o las veinticuatro de LCG. Si nos centramos exclusivamente en las infracciones muy graves, nos movemos entre las dos que establece la LISOS, o las tres la LCCM y las catorce de la LCV o las once de la LCIB.

Una misma conducta puede ser calificada como infracción de diferente gravedad en unas y otras leyes, esto ocurre con carácter habitual. Pondremos un único ejemplo, la infracción por no efectuar las dotaciones fijadas en la ley a los fondos obligatorios es calificada como grave en la mayoría de las normas y como muy grave en LCEX, la LCIB, la LCAND y la LCG.

Como decíamos antes, el principal problema de tipificación se da en la definición de las infracciones leves de carácter genérico, a las que nos referiremos, a continuación, en la clasificación de las infracciones, en el apartado denominado «Cláusula General».

Dada la amplia relación de infracciones derivada de la conjugación de las diferentes leyes, resulta imposible analizarlas todas, por lo que nos limitaremos a hacer una clasificación, no en función de su califica-

15 Respecto a la regulación de la responsabilidad en la LCV, BUZARCO SAMPER, M.: «La potestad administrativa sancionadora en la Ley 6/2003, de 24 de marzo, de Cooperativas de la Comunidad Valenciana». CIRIEC n. ${ }^{\circ} 18 / 2007$, pp. 1-32. 
ción (que como decimos, no es idéntica en todas las leyes), sino que las agruparemos por los criterios objetivos que fundamentan cada infracción. Señalaremos las que se tipifican más habitualmente sin indicar en que leyes se recogen (al ser numerosas) y aquéllas que aparecen en pocas normas, concretaremos cuáles son éstas. No incluiremos las infracciones que se refieren exclusivamente a determinadas clases de cooperativas, de las que recoge varias, p. ej., la LCAND.

\section{Clasificación de las infracciones}

\subsection{INCUMPLIMIENTO DE OBLIGACIONES FORMALES}

a) Incumplir la obligación de acreditar a los socios las aportaciones al capital social mediante títulos o libretas de participación.

b) Carecer de libros sociales o de contabilidad o el retraso en la legalización de los mismos.

c) No llevar en orden y al día los libros sociales o de contabilidad. Normalmente se fija que tal situación se produzca durante un plazo de tres o seis meses desde el último asiento practicado.

d) No formular el órgano de intervención el informe anual sobre cuentas anuales en los términos fijados por la ley aplicable.

e) Incumplimiento de la obligación de inscribir los actos que necesariamente han de ser inscritos en el Registro de Cooperativas. En algunas normas, se incluye expresamente la inscripción de los nombramientos de los cargos de los órganos sociales.

f) Incumplir la obligación de depositar las cuentas en el Registro de Cooperativas.

g) Omitir el dictamen del letrado asesor cuando fuera preceptivo (LCV y LCG).

h) Retraso en la presentación o depósito en el registro de cooperativas de los documentos exigidos por la normativa (LCG).

i) Infracciones sobre materia de denominaciones (LCV y LCMU).

j) No comunicar el traslado del domicilio de la cooperativa en un plazo de tres meses (LCE).

k) Incumplir la obligación de facilitar datos a la administración a efetos estadísticos (LCV y LCAND).

\subsection{INFRACCIONES RELATIVAS AL RÉGIMEN ECONÓMICO DE LA COOPERATIVA}

a) No efectuar las dotaciones a los fondos obligatorios en los términos establecidos en la correspondiente ley. 
b) Destinar los fondos obligatorios a finalidades distintas de las legalmente previstas.

c) Falta de auditoría de cuentas cuando resulte obligatoria por norma legal o estatutaria. La LCV califica como muy grave el incumplimiento de designar auditores de cuentas y de someter a su verificación los estados financieros y el informe sobre la gestión de cada ejercicio.

d) Asignación de retornos a personas que no son socios en activo.

e) Asignación de retornos con criterios distintos a los de la participación en las actividades sociales.

f) No figurar las dotaciones a los fondos obligatorios de forma diferenciada en la contabilidad (LCAND).

g) No finalizar las operaciones de liquidación de una cooperativa disuelta en el plazo concedido por la ley para ello (LCV).

h) Repartir los fondos sociales irrepartibles o el haber líquido resultante de la liquidación, o no distribuirlo de acuerdo con lo fijado en la norma de aplicación (LCG, LCCLM, LCEX, LCIB, LCV, LCCAT).

i) Pago a los socios de intereses superiores a los fijados por la normativa por sus aportaciones al capital social (LCCLM, LCAR, LCV, LCEX y LCG). Las dos últimas leyes citadas incluyen el pago de intereses en cuantía inferior.

j) Incumplimiento de las normas sobre la determinación de los resultados del ejercicio y de sus asignaciones. Algunas leyes lo limitan a la imputación de pérdidas. En el caso de la LCG incluye expresamente aplicar los excedentes vulnerando la ley.

k) Incumplir las normas sobre regularización de balances, actualización de aportaciones o revalorización de las mismas. Encontramos referenciados estos aspectos, aunque no en su totalidad en todas ellas, en la LCV, la LCAR, la LCEX y la LCIB.

\subsection{InFRACCIONES RELATIVAS A LOS ÓRGANOS SOCIALES}

a) No convocar la asamblea general ordinaria en tiempo y forma. Aunque ésta es la formulación habitual, algunas leyes (LCLM, LCAR y LCG) incluyen la no convocatoria de asamblea extraordinaria, cuando proceda la misma.

b) No renovar o cubrir los órganos sociales cuando corresponda (LCCLM, LCV, LCEX, LCAND, LCLR, LCG).

c) Inactividad de los órganos sociales durante un periodo de dos años.

d) Incumplimiento de las normas estatutarias en cuanto a la puntual reunión de los órganos sociales (LCV). 
e) Vulneración del derecho del personal asalariado a participar en el consejo rector (LCCM, LCEX, LCV, LCG).

f) No incluir los temas propuestos por la minoría de socios, cumpliendo las exigencias de la ley, en el orden del día de una asamblea ya convocada y no permitir el debate y votación de las propuestas efectuadas por esa minoría (LCV, LCAR), esta última incluye los temas propuestos por los interventores.

g) No designar letrado asesor (LCV).

h) Vulneración de las reglas sobre conflicto de intereses por parte de los miembros de los órganos de administración (LCV). Incluye supuestos en que puede originarse tal conflicto, tanto en realización de operaciones que puedan entrar en colisión con los intereses de la cooperativa como en la participación en la votación o adopción de acuerdos.

\subsection{SUPERACIÓN DE CIERTOS LÍMITES IMPERATIVOS IMPUESTOS POR LA LEY}

a) Superar los límites previstos en la norma aplicable para la realización de operaciones con terceros.

b) Superar los límites legales sobre contratación de trabajadores por cuenta ajena, en cooperativas de trabajo. (Único supuesto referido a una clase de cooperativa concreta que recogemos, por ser generalmente recogida en la legislación).

\subsection{InfRACCIONES QUE PUEDEN AFECTAR a LA NATURALEZA DE LA COOPERATIVA}

a) La paralización de la actividad cooperativizada durante dos años.

b) Incumplir las normas legales y estatutarias relativas al objeto y finalidad de la cooperativa (LCIB, LCCAT, LCE, LCLR, LCG y LCAND).

C) Encubrir, bajo la fórmula de sociedad cooperativa, finalidades propias de sociedades mercantiles (LCCAT y LCIB).

d) Desvirtuación de la cooperativa, cuando se violen de forma reiterada los principios cooperativos o cuando se admitan como socios a personas que legalmente no pueden serlo (LCV).

e) No proceder a la disolución de la cooperativa, cuando haya causa legal para ello (LCV).

\subsection{Actuaciones PARA OBTENER FRAUDULENTAMENTE BENEFICIOS}

a) Trasgresión de los principios cooperativos o de las disposiciones legales para lucrarse u obtener indebidamente subvenciones o bonificaciones. 


\subsection{TRASGRESIÓN DE LOS DERECHOS DE LOS SOCIOS}

a) Trasgresión generalizada de los derechos de los socios. Algunas normas lo refieren como «trasgresión no ocasional» (LCCM, LCEX, LCAND, LCLR) y la LCMU pide que la trasgresión sea «injustificada y reiterada». Estas redacciones son poco concretas y pueden generar problemas de interpretación.

b) Algunas leyes se refieren a la trasgresión en determinadas materias, tales como información, ser electores y elegibles para cargos de los órganos sociales, participar en la asamblea general y en la actividad de la cooperativa sin ninguna discriminación (LCCLM y LCG) o solamente en materia de información (LCCAT y LCIB).

\subsection{Cláusula general}

Respecto a las infracciones leves es frecuente que se haga una única tipificación para todos los supuestos merecedores de tal calificación (LISOS, LCE, LCAS, LCAR, LCMU, LCLR y LCCM) con lo cuál ésta puede resultar excesivamente genérica. En las leyes en que se tipifican varios incumplimientos merecedores de la calificación como leve, se añade, también, una cláusula general para incluir otras actuaciones merecedoras de tal calificación, pero sin ser debidamente concretadas. Así, tenemos varios supuestos:

a) Todas las trasgresiones a la ley que no estén tipificadas como infracciones graves o muy graves (LCE, LCCAT, LCLM). Estas cláusulas tan excesivamente generalistas vulneran, desde nuestro punto de vista, el principio de tipicidad.

b) Incumplimientos que afecten sólo a obligaciones formales y documentales y que no estén tipificados expresamente (LCLM, LCEX, LCCyL y LCG). Se reduce la generalidad con esta redacción al limitar los incumplimientos a aspectos documentales o formales, pero sigue siendo insuficiente para satisfacer las exigencias del principio de tipicidad.

c) Incumplimientos que no estén tipificados como graves o muy graves, afecten exclusivamente a deberes meramente formales, que no tengan trascendencia en aspectos sustantivos y no interrumpan la actividad social (LCAR). Cualquier incumplimiento de las obligaciones o la vulneración de las prohibiciones impuestas por la ley, que no supongan conflicto entre partes, no interrumpan la actividad social y no puedan ser calificadas como graves o muy graves (LCCANT). En estas dos redacciones, observamos que se concreta más el tipo, al decir, en sentido ne- 
gativo, cuando sería aplicable este precepto. Es cierto que el TC ha avalado estas descripciones por vía negativa; pero, creemos que el legislador debe de evitar esas formulaciones en favor de la seguridad jurídica.

\subsection{OBSTRUCCIÓN A LA LABOR INSPECTORA}

a) Obstaculizar la labor inspectora. En algunas leyes, se concretan algunas manifestaciones de esa obstrucción, al indicar la destrucción u ocultamiento de documentos o datos. Es calificada como grave en unas leyes (LCCLM, LCAND, LCAR y LCE) y como muy grave en otras (LCMU y LCCANT). Por su parte, la LISOS, en su artículo 50 establece que «las infracciones por obstrucción a la labor inspectora se califican como leves, graves y muy graves, en atención a la naturaleza del deber de colaboración infringido y de la entidad y consecuencias de la acción u omisión obstructora...» y concibe el tipo general por obstrucción a la labor inspectora como infracción grave, previendo que pueda ser leve, cuando impliquen un mero retraso en el cumplimiento de las obligaciones de información, comunicación o comparecencia, o muy grave en determinados supuestos que denotan una actuación especialmente relevante para impedir la labor inspectora. Esta opción parece más correcta que tipificarla siempre como grave y, especialmente, como muy grave.

\section{Prescripción de las infracciones}

En relación a los plazos de prescripción de las infracciones se aprecian, en el análisis de las leyes, dos regímenes diferentes:

- Algunas leyes contemplan dos plazos diferentes de prescripción. Uno desde que la administración tuvo conocimiento de la comisión de la infracción y otro, aplicable, en todo caso, que comienza a computar desde la fecha de la comisión. Siguen este modelo la LCE, la LCCLM y la LCG. Las dos primeras fijan el primer plazo en seis meses y la norma gallega en doce desde que la administración tuvo conocimiento de la infracción. El segundo plazo lo fijan las tres normas en tres años, dos años y un año desde la comisión de las infracciones, según sean éstas muy graves, graves o leves respectivamente.

Como podemos observar, según aprecia Martínez Maneiro, el segundo plazo es más amplio que el primero pero es lógico, ya que, el 
punto en el que empieza a contar el tiempo reflejado en la ley en uno y otro caso es distinto. En el primero, el punto de inicio es la fecha en la que la administración tuvo conocimiento de los hechos que causan la infracción, por lo tanto es muy posible que haya transcurrido cierto tiempo desde que éstos se cometieron y por lo tanto el plazo se debe acortar. Y en el segundo caso, el punto de inicio es el momento de la comisión de los hechos, no se tiene en cuenta la acción de la administración.

- El segundo modelo, es seguido por el resto de leyes aplicables y fija un único plazo de prescripción a contar desde la fecha de comisión de la infracción y fijando éste de forma diferente en función de la calificación de la infracción. Se aprecian diferencias importantes en los plazos fijados, así los más breves son los establecidos por la LCCM, la LCIB, la LCLR, la LCAS, la LCMU, la LCCyL y la LCCANT que establecen estos en tres, seis y doce meses, en función de que las infracciones sean leves, graves o muy graves, respectivamente. En el extremo opuesto, están las que fijan los plazos en un año, dos y tres años, como las leyes señaladas en el anterior supuesto y la LCAND y la LCV.

\section{Sanciones}

\section{Tipos de sanciones}

El necesario respeto al principio de tipicidad no afecta exclusivamente a las infracciones, sino también a las sanciones que por dichas conductas ilícitas se puedan imponer, siendo preciso que estén establecidas por una norma con rango de ley (artículo 129.2 de la LRJAPyPAC). La mayor parte de las leyes establecen únicamente como sanciones las de tipo pecuniario y la descalificación.

La LCV contempla la existencia de otras modalidades de sanciones:

- Prevé la amonestación para infracciones leves, que sólo se podrá imponer una sola vez por meros incumplimientos formales cometidos por simple inobservancia, cuando sean corregidos sin mediar previo requerimiento administrativo.

- Regula la sanción accesoria para la persona o entidad sancionada de obtener subvenciones $u$ otras ayudas de la Comunidad Valenciana por un periodo no superior a cinco años.

- Contempla la sanción a los administradores, consistente en la inhabilitación para desempeñar cargos cooperativos durante un periodo máximo de diez años. 
La LCCAT y la LCAR contemplan para las infracciones muy graves la sanción accesoria de exclusión, por un tiempo comprendido entre uno y tres años, de la posibilidad de obtener cualquier tipo de ayudas, bonificaciones o subvenciones de carácter público, cualquiera que sea su finalidad. Como vemos, en estos casos y a diferencia de la regulación valenciana no se limita expresamente a los supuestos en que dichas ventajas sean concedidas por la administración autonómica.

\section{Graduación y cuantía de las sanciones}

El principio de proporcionalidad obliga a que las sanciones guarden la debida adecuación entre la gravedad del hecho constitutivo de la infracción y la sanción aplicada ${ }^{16}$. Así, las infracciones leves, graves y muy graves se graduarán a efectos de determinar el importe de la sanción. Se contemplan, con carácter general, tres posibles grados, que son mínimo, medio y máximo.

Las leyes, a efectos de graduación de las infracciones, establecen una serie de criterios que deberán ser debidamente ponderados para cumplir con el principio de proporcionalidad exigible a toda potestad sancionadora. A continuación, se indican los que habitualmente se recogen en las normas:

- Número de socios afectados.

- Intencionalidad.

- Incumplimiento de advertencias o requerimientos previos.

- Perjuicios causados a los socios o a terceros.

- Repercusión social.

- Negligencia.

- Mala fe o falsedad documental.

- Capacidad económica de la cooperativa.

Se establece una cuantía mínima y máxima para las infracciones calificadas como leves, graves y muy graves; $y$, frecuentemente, se recoge expresamente en la ley una cuantía mínima y máxima para cada grado (mínimo, medio y máximo) y, en otras ocasiones, se indica que se divide, a dichos efectos, en tres tramos iguales.

Las cuantías de las sanciones son similares en la mayoría de las leyes. El abanico más amplio lo tenemos en la LCEX y en la LCIB que van

16 Principio regulado con carácter general por el artículo 131 de la Ley de Régimen Jurídico de las Administraciones Públicas y del Procedimiento Administrativo Común. 
desde los $60 €$ a los $60.000 €$. En la Comunidad Valenciana se extiende de $100 €$ a $50.000 €$, pero en la mayor parte de normas las infracciones muy graves se sancionan con un máximo de $30.000 €$.

Para evitar que deba modificarse la ley para actualizar el importe de las sanciones previstas en la misma, algunas leyes autorizan al ejecutivo, para que pueda actualizar la cuantía de las sanciones establecidas en éstas. Limitando, normalmente, esta competencia revisora de las cuantías, al exigir que se lleve a cabo teniendo en cuenta la variación de los índices de precios al consumo.

No hay unanimidad en las leyes para determinar cuál será el grado aplicable con carácter general. En la mayoría de leyes no se dice cuál será la graduación correcta si no concurren circunstancias agravantes, por lo que hay que entender que, a falta de justificación con alguno de los criterios establecidos, se deberá imponer en su grado mínimo. Expresamente, se recoge tal criterio en la LCEX, LCIB y LCAR y en las dos primeras se indica que bastará una circunstancia agravante de las contempladas en esas normas para imponerla en grado medio y dos para imponerla en grado máximo.

Se separa de este criterio la LCV que prevé que se impondrá la sanción en grado medio, si no concurre ninguna circunstancia agravante o atenuante para modificar tal graduación.

La correcta apreciación y valoración de las causas agravantes o atenuantes de la responsabilidad del infractor son fundamentales para una correcta aplicación del principio de proporcionalidad que debe informar la legislación sancionadora y la imposición de sanciones, de tal forma que se guarde la debida adecuación entre la gravedad del hecho constitutivo de la infracción y la sanción aplicada.

\section{Reincidencia}

La reincidencia es configurada como un criterio agravante a la hora de graduar una sanción, consistente, de acuerdo con el artículo 131.3.c) de la LRJAPyPAC en la comisión de más de una infracción de la misma naturaleza en el plazo de un año, cuando así haya sido declarado por resolución firme.

Diferentes leyes de cooperativas (LCV, LCIB, LCEX, LCCLM, LCCyL, LCCAT Y LCE) contemplan tal circunstancia, pero con regulaciones diversas. Así, la LCE entiende que hay reincidencia cuando se comete una infracción de igual o superior gravedad a otra, ya firme, que se haya cometido dentro del plazo de dos años, lo que endurece el régimen general antes referido. La LCCyL exige que la infracción sea del mismo 
tipo y naturaleza y la LCG, la LCEX y la LCCM una infracción del mismo tipo y calificación, en el plazo de un año. La LCIB, la LCCAT y la LCV no definen la reincidencia, limitándose a fijar los efectos cuando se aprecia la concurrencia de ésta.

Los efectos de la apreciación de la reincidencia suelen ser el incremento del importe de la sanción hasta el doble del grado de la sanción correspondiente (LCIB, LCCyL, LCEX, LCG y LCCLM), si bien, las tres primeras precisan que sin exceder del límite máximo previsto para las infracciones muy graves, o apreciarse en su grado máximo (LCV), o en un grado superior (LCCAT).

No podrá tenerse en cuenta la reincidencia como criterio agravante, cuando ésta forme parte de la tipificación de la infracción. Un ejemplo de ello, lo tenemos en el artículo 137.3.c) de la LCCyL que tipifica como infracción muy grave las infracciones graves, cuando durante los cuatro años anteriores al comienzo del correspondiente expediente sancionador, hubiera sido impuesta sanción firme por el mismo tipo de infracción. La misma redacción la encontramos en la LCMU y en la LCAR.

\section{Persistencia o continuidad en la infracción}

Esta figura se refiere a los supuestos en que una vez detectada la infracción por la administración competente para sancionarla, la sociedad cooperativa siga cometiéndola. En este caso la administración puede conminar a la empresa para que cese en la actividad infractora con apercibimiento de imponer una sanción adicional.

Contemplan este supuesto, la LCE (en la que la sanción adicional podrá alcanzar el veinte por ciento diario del importe de la multa que se haya impuesto como sanción principal), la LCV (la multa coercitiva será de un diez por ciento del importe de la sanción principal por cada semana que perdure la situación antijurídica merecedora de la sanción) y la LCCAT (que en el caso de infracción continuada califica la infracción en un grado superior y conmina a su cese mediante la sanción adicional de hasta un veinte por ciento de la sanción que se haya impuesto).

\section{Competencia}

La competencia para imponer las sanciones por la comisión de infracciones en materia de sociedades cooperativas será determinada por 
cada administración de acuerdo con su capacidad autoorganizativa. Cuanto mayor sea la gravedad de la infracción, la competencia se atribuya al titular de un órgano más elevado en la estructura jerárquica de la administración sancionadora. Esta atribución determina cuáles serán los órganos competentes para la resolución de los eventuales recursos que podrían plantearse contra las resoluciones sancionadoras.

\section{Prescripción de las sanciones}

Las únicas normas autonómicas que fijan el plazo de prescripción de las sanciones son la LCAND, que establece un año, dos años y tres años, según sean impuestas por la comisión de infracciones leves, graves o muy graves, y la LCV, que establece un único plazo de tres años.

El resto de leyes no establecen el plazo de prescripción de las sanciones, por lo que serán de aplicación los plazos previstos en el artículo 132.1 de la LRJAPyPAC ${ }^{17}$.

\section{Procedimiento sancionador}

Al tratarse de una materia en la que cada comunidad autónoma tiene competencia legislativa, ésta puede determinar, también, cuál es el procedimiento sancionador para actuar sobre esta. Algunas optan por aplicar su propio procedimiento sancionador general (LCAS). Otras leyes optan por seguir el procedimiento sancionador general establecido por la legislación estatal. La LCIB, LCMU, LCEX LCCyL LCCM LCLR y LCCANT, establecen que el procedimiento sancionador será el previsto para la imposición de sanciones en el orden social.

Esta opción supone una remisión a la normativa estatal que regula esta materia, en concreto, artículos 51 y ss. de la LISOS y Real Decreto 928/1998, de 14 de mayo, por el que se aprueba el Reglamento General sobre Procedimiento para la Imposición de las Sanciones en el Orden Social y para los Expedientes Liquidatorios de Cuotas de la Seguridad Social.

La asunción por estas leyes del referido procedimiento sancionador merece una positiva valoración. Se puede actuar de forma más efi-

17 Las sanciones impuestas por faltas muy graves prescribirán a los tres años, las impuestas por faltas graves a los dos años y las impuestas por faltas leves al año comenzando a computarse dicho plazo a partir del día siguiente a aquél en que adquiera firmeza la resolución por la que se impone la sanción. 
ciente si los órganos responsables de la función inspectora (cuando ésta se encomienda a la ITSS) y del procedimiento sancionador (cuando se atribuye la competencia al mismo órgano que otras infracciones del orden social) siguen, en esta materia, las mismas premisas de actuación que cuando actúan en materia de trabajo, empleo o de prevención de riesgos laborales y no sujetos a un procedimiento diferente exclusivo para la materia de sociedades cooperativas. Además, es un procedimiento específico para el orden social en el que creemos que tienen perfecta cabida las infracciones en materia de cooperativas

\section{Intervención temporal de la cooperativa}

Algunas normas prevén que podrán tomarse medidas de intervención temporal de la sociedad cooperativa cuando concurran circunstancias especialmente gravosas para los socios o terceros que requieren medidas urgentes que traten de evitar o reducir consecuencias graves para la propia cooperativa; y, también, por sus efectos, para su entorno social y económico. Es una figura polémica y expresión del excesivo intervencionismo administrativo propio de otras épocas. Resulta complicado encontrar el equilibrio entre las funciones otorgadas por la normativa a la administración en materia de fomento del cooperativismo y de protección de su interés social con los principios de autonomía e independencia de las sociedades cooperativas, cuando se trata de adoptar este tipo de medidas.

Regulan medidas de intervención temporal la LCEX, la LCAND, la LCG, la LCAR y la LCE.

De la lectura de estas leyes podemos decir que las medidas pueden consistir en:

- Nombramiento de uno o varios funcionarios o interventores con facultades para establecer el orden del día de la asamblea general, convocarla y presidirla.

- La intervención temporal de la cooperativa por los funcionarios o interventores designados, sin cuya aprobación los acuerdos adoptados y las decisiones tomadas por los órganos de la sociedad cooperativa no tendrán validez.

- La suspensión temporal de la actuación de los órganos sociales, nombrando uno o varios administradores provisionales que asumirán las funciones de aquéllos.

En el caso de la LCG también podrán adoptarse medidas menos drásticas consistentes en la designación de un funcionario o represen- 
tante del Consello Gallego de Cooperativas, con funciones asesoras de los órganos sociales de la cooperativa, que asistirá a tal fin a las reuniones de éstos.

La regulación prevista en la LCAND es diferente de las demás, ya que contempla las medidas de intervención como medidas provisionales para asegurar la eficacia de la resolución que pudiera recaer en un procedimiento sancionador.

\section{Descalificación}

Esta figura suscita importantes reticencias doctrinales, basadas principalmente en la previsión de que una medida tan radical como es la descalificación sea una competencia administrativa y no se conciba como una competencia judicial ${ }^{18}$. Llegando algún autor a calificar esta figura como inconstitucional, por no ajustarse a la obligación de fomento del cooperativismo, impuesta por el artículo 129.2 de la CE$^{19}$.

En cualquier caso, siempre será posible un pronunciamiento judicial al respecto, ya que todos los actos de las administraciones públicas son susceptibles de revisión por los órganos judiciales competentes.

\section{Causas de la descalificación}

Los supuestos que aparecen habitualmente recogidos en las leyes de cooperativas (no quiere decir que todos ellos aparezcan en todas las leyes) son:

a) La pérdida o incumplimiento de los requisitos necesarios para la calificación de la sociedad como cooperativa. Esta es una fórmula genérica que incluye supuestos, que en otras leyes se

18 Paz Canalejo, N.: «Comentarios al Código de Comercio y legislación mercantil especial». EDERSA tomo XX, vol. 5. 1994. Parece que dejar en manos de la administración una medida tan frágil y de tan importante calado como es la descalificación de una cooperativa no es jurídicamente lo más correcto y debiera ser la jurisdicción competente la que se encargue, al menos así opinan algunos autores que incluso bajo el principio de seguridad jurídica dudan incluso de su constitucionalidad, máxime si se considera a esta medida (descalificación firme) como una expropiación administrativa del derecho a seguir asociado a otras personas o entidades para emprender acciones de mutua ayuda.

19 Villalobos Cabrera, J.A.: «De la acción de la Administración General del Estado», en Colegios Notariales de España. Cooperativas, Comentarios a la Ley 27/1999, de 16 de julio. Tomo I. Consejo General del Notariado. Madrid 2001, pp. 809-832. 
contemplan expresamente, como los que se indican, a continuación, en las letras c), d) y e).

b) La comisión de infracciones muy graves. En este supuesto, se aprecian diversas redacciones para matizar qué infracciones son susceptibles de llevar aparejada la descalificación. Así, p.ej., la LCCLM «...cuando provoque o pueda provocar importantes perjuicios económicos o sociales, o suponga vulneración esencial de los principios cooperativos» (redacción similar en varias leyes), la LCCM «...de normas imperativas o prohibitivas de la presente ley, cuando supongan vulneración esencial de los principios cooperativos», o la LCCANT «... de normas imperativas o prohibitivas de la presente ley».

Sorprende la redacción de la LCAND, que extiende la posibilidad de ser causa de descalificación a la comisión de cualquier infracción, ya sea leve, grave o muy grave, al establecer «cualquiera de las conductas tipificadas en el artículo 123 que sean susceptibles de provocar graves perjuicios económicos o sociales, o concurra reincidencia».

c) Incurrir en determinadas causas de disolución, sin haberse procedido a acordar ésta.

d) Paralización de los órganos sociales durante un periodo de 2 años.

e) No realizar la actividad económica de la cooperativa durante dos años consecutivos.

\section{Procedimiento}

\subsection{DifERENTES PROCEDIMIENTOS PREVISTOS EN LAS NORMAS}

El procedimiento establecido, con carácter general por la mayor parte de las normas, es el establecido como procedimiento administrativo común, por la LRJAPyPAC con determinadas particularidades:

- La instrucción del expediente requerirá informe preceptivo de la ITSS Dicho informe deberá ser emitido en un plazo normalmente breve. Si no se hubiere emitido en el plazo fijado en la respectiva ley, se tendrá por evacuado.

- Se otorgará trámite de audiencia a la sociedad cooperativa. Para hacer efectivo este trámite, se personará el consejo rector o; en su defecto, un número de socios no inferior a tres. Cuando no se produjese o no fuese posible dicha comparecencia, este trámite se cumplirá publicando un anuncio en el correspondiente boletín oficial. 
Estas serían las normas comunes recogidas en todas las leyes. A partir de ahí, podemos observar peculiaridades, tales como en la LCAS y la LCCANT que exigen informe preceptivo de la organización representativa a la que pertenezca la sociedad cooperativa afectada, si consta tal circunstancia. En el caso de la LCV se contempla que el informe sea emitido por la Confederación de Cooperativas de esa comunidad autónoma. Y la LCG, LCE y LCCLM prevén la emisión de informe del correspondiente consejo de cooperativismo.

Sobre este procedimiento queremos hacer un par de reflexiones. Por un lado, se considera conveniente la petición de informe, como hemos indicado que prevén algunas leyes, a la entidad asociativa a la que figure adscrita la sociedad, o al consejo de cooperativismo o a la confederación de cooperativas. Creemos que todas las normas deberían incluir en su procedimiento actuaciones de este tipo. Este trámite garantizaría que se escuche al sector cooperativo antes de tomar una decisión tan drástica como es la descalificación.

Por otro lado, resulta llamativo que un informe, que debe emitir un órgano administrativo, la ITSS, calificado como preceptivo se entienda por evacuado si en el plazo, normalmente, de un mes no ha sido emitido, cuando la continuidad del expediente puede conllevar consecuencias tan importantes. Dada esta trascendencia, se debería prever la obligatoriedad de su emisión y constancia en el expediente, aunque para ello hubiera que otorgar un plazo mayor para evacuar dicho informe.

Se separan de ese formato general dos leyes. En la LCG se establece que el procedimiento aplicable es el previsto para la imposición de sanciones en el orden social y las normas del procedimiento administrativo común.

La misma opción que sigue la LCCANT, pero, donde se establecen claramente dos procedimientos diferentes, en función de que la causa de la descalificación sea por la pérdida o incumplimiento de los requisitos necesarios para la calificación de la sociedad como cooperativa o sea por la imposición de tal sanción por la comisión de una infracción muy grave. En el primer caso, se ajustará a las disposiciones previstas en la LRJAPyPAC, con las particularidades que referíamos anteriormente. Para el segundo supuesto, remite al procedimiento previsto para la imposición de sanciones en el orden social, al contemplarlo como un supuesto más de comisión de infracción y consiguiente sanción. 


\subsection{SUBSANACIÓN}

Este trámite, consiste en que una vez constatada, por la administración competente, la causa de descalificación, se otorga por ésta a la cooperativa un plazo determinado (normalmente de seis meses) para dejar de incurrir en esa situación irregular, antes de iniciar el expediente de descalificación. Esta figura está prevista en la LCE, la LCV, la LCIB, la LCCLM, la LCCM, la LCCAT y la LFCN.

El hecho de que no se contemple expresamente no quiere decir que el resultado de la incoación del expediente sea, en todo caso, la descalificación, ya que iniciado el expediente, en cualquier momento, la cooperativa podrá acreditar que ha dejado de incurrir en la causa que motiva esta actuación; y, constatada tal circunstancia por la administración, ésta no deberá resolver acordando la descalificación.

\section{Efectos}

Cuando adquiera firmeza la descalificación surtirá efectos registrales de oficio e implicará la disolución de la sociedad cooperativa. Esta conclusión tan drástica se ve matizada por algunas normas que suavizan los radicales efectos de la descalificación al permitir que la sociedad cooperativa descalificada se transforme en un periodo de tiempo (normalmente de seis meses). Si transcurrido ese plazo, no se ha transformado, la cooperativa se disolverá de manera forzosa. Esta figura de la transformación es contemplada expresamente por la LCE, la LCV, la LCCLM y la LCCM.

Por último indicar que la LFCN exige la publicación de la orden foral de descalificación.

\section{$\mathrm{XI}$. Conclusiones}

La pluralidad normativa que se da en España en materia de sociedades cooperativas, llega no solo a los aspectos relativos a la configuración de este tipo societario, sino también al marco de las relaciones que se establecen entre la administración y estas sociedades, incluidas las relativas a la función inspectora. Así tenemos normas que tipifican muchos más incumplimientos como infracciones que otras, calificaciones distintas para una misma conducta, diversidad de cuantías de las sanciones, diferentes procedimientos (incluida la atribución de la función inspectora), plazos de prescripción,... lo que nos lleva a concluir 
que existen notables diferencias en los grados de severidad de las leyes y esto nos dibuja un marco que no parece el más óptimo.

Pero, lo más importante es que las normas cumplan con los principios de la potestad y del procedimiento sancionador; $y$, en este sentido aún puede mejorarse, evitando tipificaciones genéricas, procurando conseguir que las sanciones sean proporcionales al incumplimiento cometido...

La doctrina desconfía de la aplicación eficaz del régimen disciplinario administrativo, justificando esta valoración en lo que la experiencia, manifiestan, demuestra. Consideran que resulta más efectivo el control de la auditoría de cuentas, el arbitraje cooperativo y la actuación de los tribunales ${ }^{20}$. Y es que realmente las actuaciones inspectoras que se realizan en materia de cooperativas son muy escasas, si nos ceñimos al ámbito de competencias de la ITSS, como se deduce de su informe anual de $2013^{21}$, pese al frecuente uso de la máscara de cooperativa que hacen determinadas empresas para camuflar una realidad muy diferente.

\section{Bibliografía}

BuzARCo SAmper, M.: "La potestad administrativa sancionadora en la Ley 6/2003, de 24 de marzo, de Cooperativas de la Comunidad Valenciana». CIRIEC n. ${ }^{\circ}$ 18/2007, pp. 1-32.

Calvo Ortega, R.: «Las figuras de la Economía Social en la Constitución Española de 1978». CIRIEC-España, n. ${ }^{\circ} 47,2003$, pp. 159-174.

Divar, J.: «Introducción al cooperativismo, en I Jornadas de Cooperativas de Euskadi, 1882.

García Trascasas, A. y Reguero Celada, J.: "La Inspección de Trabajo ante el hecho cooperativo. La descalificación de las cooperativas», en Economía social y cooperativismo (directora MORGADO PANADERO, P. y coordinadora BURGOS RosADO, L.). Editorial Lex Nova, S.A. 2006. pp. 251-275.

GIRÓN, J.: "Los conceptos y tipos de sociedad en los Códigos Civil y de Comercio y sus relaciones», en Estudios del Centenario de la Ley del Notariado, Madrid, 1964.

20 Morillas Jarillo, M.J. y Feliú Rey, M.I.: Curso de Cooperativas, 2. ${ }^{a}$ edición. Tecnos 2002.

21 Las actuaciones en materia de cooperativas y sociedades laborales (ambas se cuantifican conjuntamente) ascienden a 274, sobre un total de 137.154 realizadas exclusivamente en el capítulo de relaciones laborales (no se incluyen las materias de prevención de riesgos laborales, empleo y colocación, extranjería y seguridad social). Las infracciones recogidas en las correspondientes actas son 8 , de un total de 5.776 y se han realizado 7 requerimientos en esta materia de un total de 21.918 (datos de actas y requerimientos sólo referidos al área de relaciones laborales). 
Llobregat, M.L.: Mutualidad y empresas cooperativas, Bosch, Barcelona, 1990.

MARTínez MANeiro, B.: «Estudio del régimen de inspección y sanción en la Ley de Sociedades Cooperativas de Euskadi y comparativa con la regulación de esta materia en el resto de leyes cooperativas autonómicas vigentes y la ley estatal». GEZKI, n. ${ }^{\circ}$ 3, 2007, pp. 41-63.

Morillas Jarillo, M.J. y Feliú Rey, M.I.: Curso de Cooperativas, 2. ${ }^{a}$ edición. Tecnos 2002.

Paz-Ares, C.: Comentario del Código Civil, tomo II, 2. ${ }^{\circ}$ ed., Civitas, Madrid, 1993.

Paz Canalejo, N.: "Comentarios al Código de Comercio y legislación mercantil especial». EDERSA tomo XX, vol. 5. 1994.

Rodrigo RuIz, M.A.: "Mandato constitucional de fomento y fiscalidad de las cooperativas» CIRIEC-España, Revista de Economía Pública, Social y Cooperativa, n. $^{\circ} 47$, extraordinario, noviembre de 2003, pp. 199-219.

Villalobos Cabrera, J.A.: «De la acción de la Administración General del Estado», en Colegios Notariales de España. Cooperativas, Comentarios a la ley 27/1999, de 16 de julio. Tomo I. Consejo General del Notariado. Madrid 2001, pp. 809-832. 